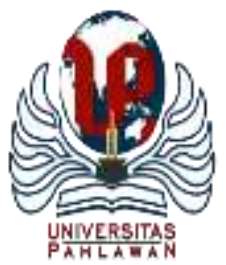

Edukatif : Jurnal Ilmu Pendidikan Volume 4 Nomor 1 Tahun 2022 Halm 94 - 100

EDUKATIF: JURNAL ILMU PENDIDIKAN

Research \& Learning in Education

https://edukatif.org/index.php/edukatif/index

\title{
Manajemen Pendidikan Inklusi di Sekolah Dasar
}

\author{
Syaiful Bahri ${ }^{\bowtie}$ \\ UIN Antasari Banjarmasin, Indonesia \\ E-mail : syaifulbahri@uin-antasari.ac.id
}

\begin{abstract}
Abstrak
Tujuan penelitian ini adalah untuk mengetahui manajemen pendidikan inklusi di SD Negeri 2 Barabai Kabupaten Hulu Sungai Tengah. Penelitian ini merupakan jenis penelitian kualitatif deskriptif. Subjek dari penelitian ini dipilih secara purposive sampling. Teknik pengumpulan data meliputi: observasi, wawancara, dan dokumentasi. Subjek penelitian adalah komite sekolah, kepala sekolah, guru pendamping anak berkebutuhan khusus, anak berkebutuhan khusus, dan orang tua anak berkebutuhan khusus. Tekhnik analisis data menggunakan data collection, data reduction, data display, dan verifying. Hasil penelitian menunjukkan bahwa manajemen pendidikan inklusi di SD Negeri 2 Barabai Kabupaten Hulu sungai tengah baik. Hal ini dibuktikan dengan verifikasi data dengan rubrik penilaian data, bahwa dari hasil observasi, wawancara, serta dokumentasi menunjukkan bahwa manajemen pendidikan inklusi di SD Negeri 2 barabai terdiri dari 8 ruang lingkup, yaitu manajemen kurikulum, manajemen peserta didik, manajemen pembiayaan, manajemen pendidik dan tenaga kependidikan, manajemen hubungan masyarakat, manajemen budaya dan lingkungan sekolah, dan manajemen layanan khusus.
\end{abstract}

Kata Kunci: Pendidikan inklusi, manajemen pendidikan, sekolah dasar.

\begin{abstract}
The purpose of this study was to determine the management of inclusive education in SD Negeri 2 Barabai, Hulu Sungai Tengah Regency. This research is a type of descriptive qualitative research. The subjects of this study were selected by purposive sampling. Data collection techniques include observation, interviews, and documentation. The research subjects were school committees, school principals, accompanying teachers for children with special needs, children with special needs, and parents of children with special needs. Data analysis techniques use data collection, data reduction, data display, and verifying. The results showed that the management of inclusive education at SD Negeri 2 Barabai, Hulu Sungai Tengah Regency was good. This is evidenced by the verification of the data with the data assessment rubric, that the results of observations, interviews, and documentation show that the management of inclusive education at SD Negeri 2 Barabai consists of 8 scopes, namely curriculum management, student management, financing management, educator management and education personnel, public relations management, school culture and environment management, and special services management.
\end{abstract}

Keywords: Inclusive education, education management, elementary school.

Copyright (c) 2022 Syaiful Bahri

$\triangle$ Corresponding author:

Email : syaifulbahri@uin-antasari.ac.id

DOI : https://doi.org/10.31004/edukatif.v4i1.1754 ISSN 2656-8071 (Media Online)

Edukatif : Jurnal Ilmu Pendidikan Vol 4 No 1 Tahun 2022

p-ISSN 2656-8063 e-ISSN 2656-8071 


\section{PENDAHULUAN}

Pendidikan adalah setiap usaha, pengaruh, perlindungan dan bantuan yang diberikan kepada anak. Bantuan yang diberikan kepada anak yang dimaksud disini adalah usaha seseorang untuk mengajarkan atau membina kecerdasan materi, budi pekerti, perilaku sosial, cara berinteraksi dengan orang lain, dan olah emosional pada diri anak sehingga anak dapat berperilaku sesuai dengan aturan-aturan yang ada di dalam lingkungan sosialnya (Sholawati, 2019). Pada hakekatnya pendidikan tidak hanya melulu soal teoritis saja akan tetapi usaha pendidik untuk mendidik peserta didik harus bertanggungjawab terhadap moral peserta didik dan sesuai dengan manajemen/strategi yang terencana dengan baik sebagai landasan pendidik untuk membangun karakter peserta didik. Pendidikan dapat berlangsung di dalam lingkungan sosial, tidak harus dengan lingkup lingkungan sosial yang luas. Ketika anak melakukan sebuah interaksi dengan orang lain, kepada keluarga, guru, maupun teman-temannya, maka di dalam interaksi tersebut terdapat kegiatan pendidikan yang berlangsung (Manajemen Pendidikan Inklusi, 2015). Dalam Undang-Undang Nomor 20 Tahun 2003 Tentang Sistem Pendidikan Nassional diterangkan bahwa setiap warga negara Republik Indonesia mempunyai kesempatan yang sama untuk memperoleh pendidikan, tak terkecuali bagi anak berkebutuhan khusus (Lukitasari et al., 2017). Oleh karena itu anak-anak dengan kebutuhan khusus seperti tuna netra, tuna rungu, tuna grahita, tuna daksa, tuna laras, anak kesulitan belajar, dan anak inklusi berhak mendapatkan pendidikan yang sama dengan anak lain. Hak asasi manusia yang menegaskan bahwa pendidikan merupakan hak asasi yang paling dasar dari anak-anak, membuat pendidik berusaha untuk lebih giat dan memperluas akses pendidikan kepada semua siswa dalam berbagai latar belakang (Ikramullah \& Sirojuddin, 2020). Perluasan pendidikan tidak hanya dilakukan oleh pendidik dalam hal ini guru atau sekolah, namun membutuhkan peran serta dari keluarga, masyarakat, dan negara yang diharapkan mampu menuntaskan kesenjangan pendidikan yang ada di Indonesia (Siswanto \& Susanti, 2019).

Program pendidikan inklusi sudah diterapkan berorientasi terhadap pelayanan kepada anak, sehingga kebutuhan setiap anak terpenuhi. Program pendidikan inklusi tidak hanya diterapkan pada anak yang memiliki kebutuhan khusus tetapi untuk semua anak karena pada dasarnya setiap anak memiliki karakteristik, keunikan, dan keberagamaan secara alamiah sudah ada pada diri anak. Karakteristik setiap anak ini yang harus difasilitasi dalam semua jenjang pendidikan pada umumnya dan pendidikan anak usia dini pada khususnya. Undang-Undang Nomor 20 tahun 2003 tentang sistem pendidikan nasional yang mengatur setiap warga negara mempunyai hak yang sama untuk mendapatkan pendidikan dasar yang bermutu baik yang mengalami kelainan fisik, mental, emosional, intelektual, memiliki bakat istimewa, dan yang tinggal di daerah terpencil. Undang-Undang tentang sistem pendidikan ini menjelaskan bahwa pendidikan inkusi tidak hanya untuk anakanak yang mengalami kebutuhan secara fisik tetapi juga untuk anak-anak yang mempunyai kebudayaan, sosial, geografi dan bahasa yang berbeda untuk mendapatkan layanan pendidikan yang sama sesuai kebutuhan setiap anak sehingga dapat menstimulai perkembangan, pengetahuan dan keterampilan anak (Setianingsih, 2018).

Anak Berkebutuhan Khusus (ABK) biasanya bersekolah di Sekolah Luar Biasa (SLB) sesuai dengan kekhususannya masing-masing. Dalam rangka menanggulangi hal tersebut, maka perlu dilakukan suatu terobosan berupa pemberian kesempatan dan peluang kepada anak-anak berkelainan untuk memperoleh pendidikan di sekolah umum (Rusmono, 2020). Pola pendidikan seperti ini disebut pendidikan inklusi (Wati, 2014). Inklusi dapat dipandang sebagai suatu proses untuk menjawab dan merespon keragaman di antara semua individu melalui peningkatan partisipasi dalam belajar, budaya dan masyarakat dan mengurangi ekslusi baik dalam maupun dari kegiatan pendidikan (Wathoni, 2013). Inklusi melibatkan perubahan dan modifikasi isi, pendekatan, struktur dan strategi dalam sistem reguler dengan suatu visi bersama bahwa inklusi adalah tanggung jawab mendidik semua anak yang berada pada rentangan usia yang sama (UNESCO, 1994). Inklusi merupakan suatu sistem yang hanya dapat diterapkan ketika semua warga sekolah memahami dan mengadopsinya. Pendidikan inklusif berkenaan dengan memberikan respon yang sesuai kepada spektrum 
yang luas dari kebutuhan belajar baik dalam setting pendidikan formal maupun non formal. Pendidikan inklusif merupakan pendekatan yang yang memperhatikan bagaimana mentransformasikan sistem pendidikan sehingga mampu merespon keragaman siswa. Pendidikan inklusif bertujuan dapat memungkinkan guru dan siswa untuk merasa nyaman dengan keragaman dan melihatnya lebih sebagai suatu tantangan dan pengayaan dalam lingkungan belajar dari pada suatu problem (Sastradiharja et al., 2020).

Untuk memberikan kesempatan pada kelompok difable agar menjadi setara dengan kelompok dalam mengakses dan mendapatkan hak dalam mengenyam pendidian sebagai kebutuhan dasar, maka diperlukan sebuah ideologi, teori sosial yang dapat dijadikan paradigma dalam memecahkan dan menguraikan ketimpangan dan disparitas yang cukup lebar yang selama ini mengeksklusi mereka dari kelompok mainstream. Tiga paradigmatik itu adalah sebagai berikut: (a) paradigma konservatif, (b) paradigma liberal, (c) paradigma kritis mana (Putri \& Harmanto, 2020).

Kondisi di lapangan masih banyak sekolah-sekolah pada umumnya untuk melaksanakan program pendidikan inklusi. Selain ketidaksiapan sumber daya manusia dan sarana prasarana, ketidaktahuan tentang tujuan dan manfaat yang diperoleh anak baik anak normal maupun anak yang memiliki kebutuhan. Pelaksanaan pendidikan di lapangan cenderung menilai bahwa jika anak berkebutuhan khusus diberikan pelayanan pendidikan yang sama dan bersamaan dengan anak normal maka hanya akan mengganggu proses pendidikan dan pengaruh tidak baik pada anak normal. Pola pendidikan seperti ini akan membawa dampak pada anak baik anak berkebutuhan khusus maupun anak normal, yaitu apatis, tidak menghormati, tidak percaya diri, individualisme, dan tidak siap hidup dimasyarakat. Padahal program pendidikan inklusi ini memberikan pendidikan tentang nilai perbedaan dan keberagamaan sehingga anak-anak akan saling menghormati dan membantu satu sama lain sebagai bekal menghadapi kehidupan bermasyarakat. Hal ini sesuai dengan konsep negara Indonesia, yaitu memiliki berbagai keberagaman budaya, bahasa, sosial, geografi, agama, dsb. Semua itu yang harus kita ajarkan kepada anak usia dini secara konkret melalui program pendidikan inklusi.

\section{METODE PENELITIAN}

Penelitian ini menggunakan metode kualitatif. Hal ini, sebuah pendekatan atau pencarian untuk menyelidiki dan memahami fenomena sentral (Raco, 2018). Penelitian kualitatif (qualitative research) adalah suatu penelitian yang ditujukan untuk mendiskripsikan dan menganalisis fenomena, peristiwa, aktivitas sosial, sikap, kepercayaan persepsi, pemikiran orang secara individual maupun kelompok. Penelitian kualitatif bersifat induktif maksudnya peneliti membiarkan permasalahan-permasalahan muncul dari data atau dibiarkan terbuka untuk interpretasi (Dr. Tjipto Subadi, 2006). Data dihimpun dengan pengamatan yang seksama, mencakup deskripsi dalam konteks yang mendetail disertai catatan-catatan hasil wawancara yang mendalam, serta hasil analisis dokumen dan catatan-catatan (Khadijah, 2018).

Sifat dari penelitian ini adalah penelitian kepustakaan, dan penelitian kepustakaan berarti penelitian yang utamanya menargetkan buku-buku dan literatur lainnya. Penelitian kepustakaan mengumpulkan informasi dan data secara rinci melalui berbagai buku, catatan, jurnal, dan daftar pustaka lainnya, serta hasil pekerjaan sebelumnya yang berkaitan dengan jawaban atas masalah yang akan diteliti dan landasan teori (Yaniawati, 2020). Penelitian ini menghasilkan informasi berupa catatan dan data deskriptif yang terdapat di dalam teks yang diteliti.

Penelitian kualitatif membutuhkan analisis teknis. Metode analisis teknis memberikan penjelasan dan informasi yang jelas, objektif, sistematis dan analitis, kritis tentang upaya peningkatan kualifikasi guru melalui pelatihan selama periode fundamental. Pendekatan kualitatif memberikan klasifikasi dan penjelasan berikut berdasarkan tahap awal pengumpulan data yang diperlukan.

Sebagai penelitian kepustakaan, maka terdapat dua macam sumber data yang akan dijelaskan, yakni: 
1. Sumber Primer

Sumber primer adalah sumber data pokok yang langsung dikumpulkan peneliti dari objek penelitian, yaitu buku, artikel, yang menjadi objek dalam penelitian ini.

2. Sumber Sekunder

Adalah sumber data tambahan yang menurut peneliti menunjang data pokok, yaitu buku atau artikel yang berperan sebagai pendukung buku atau artikel primer untuk menguatkan konsep yang ada di dalam buku atau artikel primer.

Metode yang digunakan untuk mengumpulkan data penelitian dalam penelitian kepustakaan adalah dengan memilih, mencari, menyajikan, dan menganalisis data kepustakaan. Lembaga kajian ini adalah untuk menemukan bahan pustaka yang substansinya memerlukan pengolahan filosofis dan teoritis. Penelusuran literatur di sini adalah studi literatur tanpa verifikasi empiris Data yang disajikan merupakan data berbentuk kata yang perlu diolah agar ringkas dan sistematis (Dr. Sandu Siyoto, SKM., M.Kes \& Ali Sodik, 2015).

Dalam penelitian ini menggunakan teknik analisis data berupa analisis isi (content analysis). Analisis isi merupakan analis ilmiah tentang isi pesan suatu data. Analisis adalah serangkaian upaya sederhana tentang bagaimana data penelitian pada gilirannya dikembangkan dan diolah ke dalam kerangka kerja sederhana. Data yang sudah terkumpul kemudian dianalisis untuk mendapatkan informasi, namun terlebih dahulu data tersebut diseleksi atas dasar reliabilitasnya Tujuan dari analisis data ini adalah untuk mencari kebenaran dari data-data yang telah diperoleh, sehingga dari sini bisa ditarik kesimpulan dari hasil penelitian yang telah dilakukan. Dalam penelitian ini, peneliti menggunakan 3 tahapan, yaitu: reduksi data, display data, verifikasi data dan mengambil kesimpulan.

\section{HASIL DAN PEMBAHASAN PENELITIAN}

Semua siswa yang layak atas pendidikan khusus harus mendapatkan pendidikan yang dirancang secara khusus atau specially designed instruction (SDI). SDI dibuat untuk memenuhi kebutuhan individual siswa penyandang disabilitas. SDI dipantau secara cermat dan setiap kemajuan yang berkaitan dengan pengajaran harus di dokumentasikan. Pembelajaran khusus ini tidak hanya menyinggung masalah keterampilan komunikasi, tentang perilaku, keterampilan interaksi sosial, keterampilan vokasi atau fungsional, atau ranah apapun yang sekiranya terkena dampak dari kondisi disabilitas (Tarnoto, 2016).

Pendidikan inklusi merupakan pendidikan yang berusaha mengakomodasi segala jenis perbedaan dari peserta didik, termasuk anak berkebutuhan khusus. Secara konseptual dan paradigmatis, pendidikan inklusif memiliki karakter akomodatif, dengan menerima setiap siswa dan menghindari labeling negatif, serta dalam operasionalnya melibatkan pihak-pihak terkait secara aktif (Agustin, 2017).

Manajemen merupakan kegiatan atau rangkaian kegiatan yang dilakukan dari, oleh dan bagi manusia. Rangkaian kegiatan itu merupakan suatu proses pengelolaan dari suatu rangkaian kegiatan pendidikan yang sifatnya kompleks dan unik yang berbeda dengan tujuan perusahaan untuk memperoleh keuntungan yang sebesar-besarnya (Sulistyaningsih, 2021). Manajemen pendidikan pada prinsipnya merupakan suatu bentuk penerapan manajemen atau administrasi dalam mengelola, mengatur dan mengalokasikan sumber daya yang terdapat dalam dunia pendidikan. Hal ini senada dengan pernyataan Nurhadi yang menyatakan bahwa manajemen pendidikan adalah suatu ilmu yang yang mempelajari penataan Sumber Daya Manusia (SDM), kurikulum, atau sumber belajar dan fasilitas untuk mencapai tujuan pendidikan secara optimal dan menciptakan suasana yang baik bagi manusia, yang turut serta dalam pencapaian pendidikan yang telah disepakati (Marlia, 2018).

Manajemen pendidikan inklusi adalah suatu proses perencanaan (planning), pengorganisasian (organizing), penggerakan (actuating), dan pengawasan (controlling) dalam penyelenggaraan sistem pendidikan inklusi untuk mencapai tujuan yang telah ditetapkan. Manajemen pendidikan pada sekolah inklusi memberikan kewenangan penuh kepala sekolah untuk merencanakan, mengorganisasikan, mengarahkan, mengkoordinasikan, mengawasi dan mengevaluasi komponen-komponen pendidikan suatu sekolah yang 
meliputi siswa, kurikulum, tenaga kependidikan, sarana dan prasarana pendidikan, pembiayaan pendidikan dan hubungan antara masyarakat dan sekolah (Shofa, 2018).

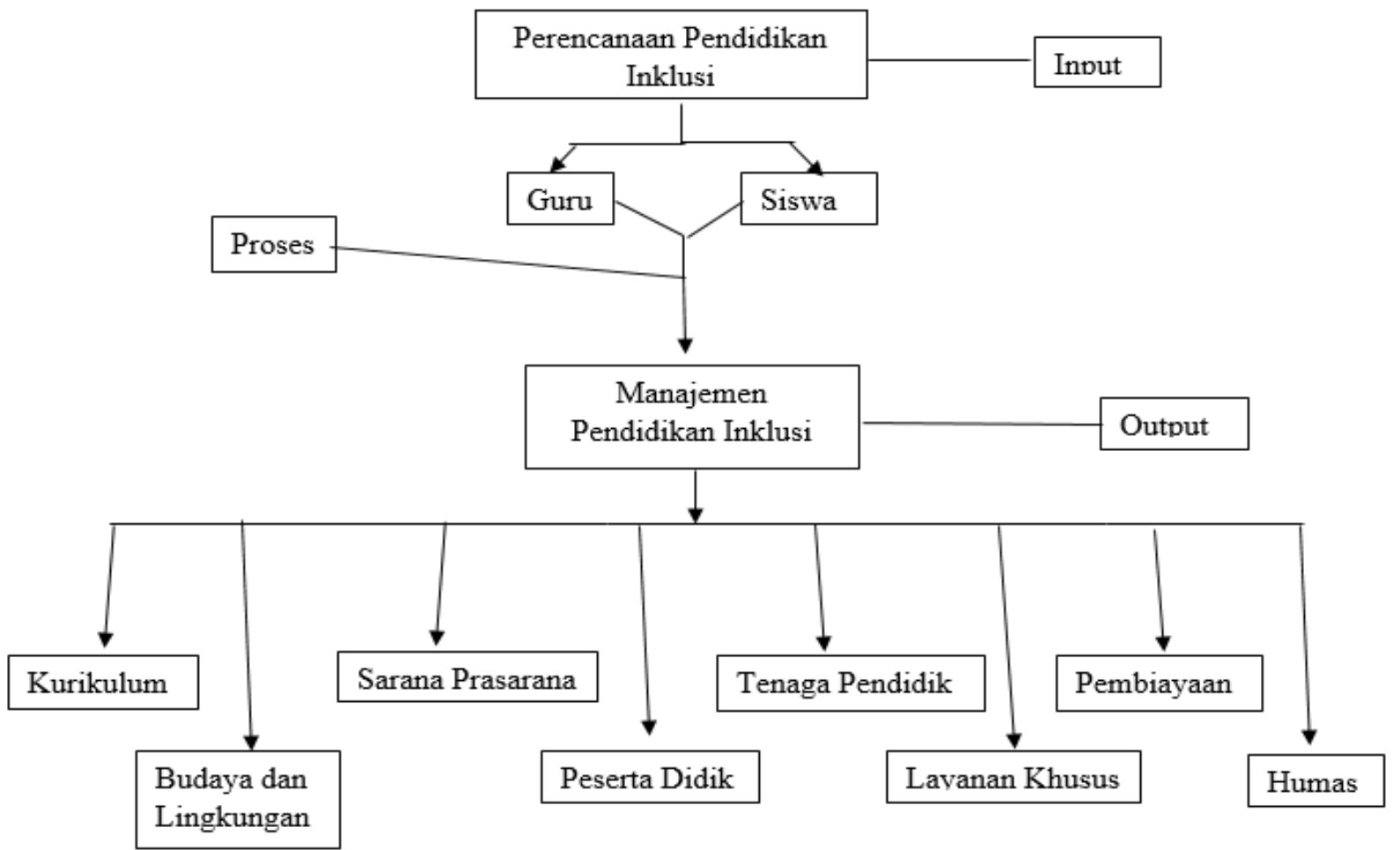

Gambar 1. Manajemen pendidikan inklusi

Berdasarkan kerangka pemikiran (Gambar 1) yang dibuat oleh penulis, menjelaskan bahwa input dari penelitian ini adalah sebuah perencanaan pendidikan inklusi di SD Negeri 2 barabai Kabupaten hulu sungai tengah. Sementara proses yang dilakukan dalam manajemen pendidikan inklusi melalui guru dan peserta didik. Output dari manajemen pendidikan inklusi adalah mendeskripsikan bagaimana ruang lingkup manajemen pendidikan inklusi di SD Negeri 2 barabai Kabupaten hulu sungai tengah.

Manajemen pendidikan inklusi di SD Negeri 2 barabai memuat 8 ruang lingkup seperti; manajemen kurikulum dan pembelajaran, manajemen peserta didik, manajemen pendidik dan tenaga kependidikan, manajemen hubungan masyarakat, manajemen sarana dan prasarana, manajemen pembiayaan, manajemen budaya dan lingkungan sekolah, serta manajemen layanan khusus. Dari kedelapan ruang lingkup manajemen yang berada di sekolah inklusi tersebut, menunjukkan bahwa sekolah inklusi di SD Negeri 2 barabai baik sesuai dengan apa yang telah dilaksanakan, akan tetapi campur tangan dari pemerintah dan dinas pendidikan belum menunjukkan adanya kerjasama yang baik dalam menunjang pendidikan inklusi di SD Negeri 2 barabai. Sekolah inklusi di SD Negeri 2 barabai dapat dikategorikan baik, hal ini ditunjukkan dengan hasil wawancara peneliti dengan kepala sekolah dan guru pendamping anak berkebutuhan khusus menjelaskan mengenai 8 ruang lingkup manajemen sekolah inklusi yang ada di SD Negeri 2 barabai baik, akan tetapi campur tangan dari pemerintah ataupun dinas pendidikan belum optimal. Hasil observasi yang dilakukan oleh peneliti menunjukkan bahwa dari 8 manajemen pendidikan inklusi di SD Negeri 2 barabai khususnya manajemen peserta didik, manajemen sarana dan prasarana menunjukkan bahwa sekolah inklusi di SD Negeri 2 barabai menunjukkan sekolah yang ramah terhadap siswa inklusi.

\section{KESIMPULAN}

Manajemen pendidikan inklusi SD Negeri 2 barabai memuat 8 ruang lingkup seperti; manajemen kurikulum dan pembelajaran, manajemen peserta didik, manajemen pendidik dan tenaga kependidikan, manajemen hubungan masyarakat, manajemen sarana dan prasarana, manajemen pembiayaan, manajemen 
budaya dan lingkungan sekolah, serta manajemen layanan khusus. Dari kedelapan ruang lingkup manajemen yang berada di sekolah inklusi tersebut, menunjukkan bahwa sekolah inklusi di SD Negeri 2 barabai baik sesuai dengan apa yang telah dilaksanakan, akan tetapi campur tangan dari pemerintah dan dinas pendidikan belum menunjukkan adanya kerjasama yang baik dalam menunjang pendidikan inklusi di SD Negeri 2 barabai.

\section{DAFTAR PUSTAKA}

Agustin, I. (2017). Manajemen Pendidikan Inklusi Di Sekolah Dasar Sumbersari 1 Kota Malang. Education and Human Development Journal, 1(1). https://doi.org/10.33086/ehdj.v1i1.290

Dr. Sandu Siyoto, SKM., M.Kes \& Ali Sodik, M. . (2015). Dasar Metodologi Penelitian. In Ayup (Ed.), วารสารสังคมศาสตร์วิชาการ (Vol. 7, Issue 2). Literasi Media Publishing.

Dr. Tjipto Subadi, M. S. (2006). Metode Penelitian Kualit (E. F. Hidayati (Ed.)). Penerbit Muhammadiyah University Press.

Ikramullah, I., \& Sirojuddin, A. (2020). Optimalisasi Manajemen Sekolah Dalam Menerapkan Pendidikan Inklusi di Sekolah Dasar. Munaddhomah: Jurnal Manajemen Pendidikan Islam, 1(2), 131-139. https://pasca.jurnalikhac.ac.id/index.php/munaddhomah/article/view/36

Khadijah, S. (2018). Efektivitas Pelatihan Kompetensi Dalam Peningkatan Kinerja Guru Di Smpn 1 Batang Gangsal. Jurnal Mitra Manajemen, 1(2), 151-163. https://doi.org/10.52160/ejmm.v1i2.20

Lukitasari, S. W., Sulasmono, B. S., \& Iriani, A. (2017). Evaluasi Implementasi Kebijakan Pendidikan Inklusi. Kelola: Jurnal Manajemen Pendidikan, 4(2), 121. https://doi.org/10.24246/j.jk.2017.v4.i2.p121-134

Manajemen Pendidikan Inklusi. (2015). 1-10.

Marlia, L. (2018). Manajemen pendidikan inklusif di sekolah Dasar islam terpadu Annida Sokaraja Banyumas. Thesis. https://jurnal.untirta.ac.id

Putri, A. F. S., \& Harmanto, H. (2020). Manajemen Pendidikan Inklusi dalam Penanaman Karakter Tanggung Jawab pada Mata Pelajaran PPKn di SMP Pendahuluan Pendidikan karakter sangat penting dibutuhkan oleh peserta didik dalam era globalisasi saat ini . 1 Karakter yang perlu ditekankan pada pesert. 6(1), 106-118.

Raco, J. (2018). Metode penelitian kualitatif: jenis, karakteristik dan keunggulannya. https://doi.org/10.31219/osf.io/mfzuj

Rusmono, D. O. (2020). Optimalisasi Pendidikan Inklusi di Sekolah: Literature Review. Kelola: Jurnal Manajemen Pendidikan, 7(2), 209-217. https://ejournal.uksw.edu/kelola/article/view/2859/1621

Sastradiharja, E. J., MS, F., \& Sutarya, M. (2020). Pendidikan Inklusi di Perguruan Tinggi: Studi Pada Pusat Kajian dan Layanan Mahasiswa Berkebutuhan Khusus Politeknik Negeri Jakarta. Alim Journal of Islamic, I(2), 1-118.

Setianingsih, E. S. (2018). Implementasi Pendidikian Inklusi: Manajemen Tenaga Kependidikan (Gpk). Malih Peddas (Majalah Ilmiah Pendidikan Dasar), 7(2), 126. https://doi.org/10.26877/malihpeddas.v7i2.1808

Shofa, M. F. (2018). Implementasi Manajemen Pendidikan Inklusi di PAUD Inklusi Saymara Kartasura. AtTarbawi: Jurnal Kajian Kependidikan Islam, 3(2). https://doi.org/10.22515/attarbawi.v3i2.1337

Sholawati, S. A. (2019). Manajemen Pembelajaran Pendidikan Inklusi Pada Anak Berkebutuhan Khusus Di SDN Kalirungkut-1 Surabaya. Abdau: Jurnal Pendidikan Madrasah Ibtidaiyah, 2(1), 39-60. https://doi.org/10.36768/abdau.v2i1.24

Siswanto, S., \& Susanti, E. (2019). Manajemen Pengembangan Kurikulum Sekolah Inklusi. Tadbir: Jurnal Studi Manajemen Pendidikan, 3(2), 113. https://doi.org/10.29240/jsmp.v3i2.927

Sulistyaningsih, M. (2021). Manajemen Pendidikan Inklusi di SMP Islam Al-Irsyad Cilacap.

Tarnoto, N. (2016). Permasalahan-Permasalahan Yang Dihadapi Sekolah Penyelenggara Pendidikan Inklusi 
100 Manajemen Pendidikan Inklusi di Sekolah Dasar-Syaiful Bahri

DOI: https://doi.org/10.31004/edukatif.v4i1.1754

Pada Tingkat SD. Humanitas, 13(1), 50. https://doi.org/10.26555/humanitas.v13i1.3843

Wathoni, K. (2013). Implementasi Pendidikan Inklusi dalam Pendidikan Islam. Ta'allum: Jurnal Pendidikan Islam, 1(1). https://doi.org/10.21274/taalum.2013.1.1.99-109

Wati, E. (2014). Manajemen Pendidikan Inklusi Di Sekolah Dasar Negeri 32 Kota Banda Aceh. Jurnal Ilmiah Didaktika, 14(2), 368-378. https://doi.org/10.22373/jid.v14i2.508

Yaniawati, P. (2020). Penelitian Studi Kepustakaan. Penelitian Kepustakaan (Liberary Research), April, 15. 